\title{
Etching Method for the Microstructure of LTCC
}

\author{
Feng Yuan \\ School of Materials Science and Engineering, Tianjin Polytechnic University \\ Tianjin 300160, China \\ E-mail: yf-0514@163.com
}

\begin{abstract}
$1 \mathrm{wt} \%$ hydrochloride acid ( $\mathrm{HCl}), 2 \mathrm{wt} \%$ hydrofluoric acid (HF), $10 \mathrm{wt} \%$ hydro nitride acid $\left(\mathrm{HNO}_{3}\right)$, and $19 \mathrm{wt} \%$ sodium hydroxide $(\mathrm{NaOH})$, were used to etch the LTCC. The SEM analysis shows that the microstructure of the LTCC A6 (Ferro) can be obtained through the etching of the 19wt\% sodium hydroxide. The XRD analysis confirmed that the glass phase can be selectively removed from the glass ceramics in a $19 \mathrm{wt} \%$ sodium hydroxide aqueous solution at room temperature after $20 \mathrm{hrs}$.
\end{abstract}

Keywords: LTCC, Polishing, Etching

\section{Introduction}

Recently, the Low-temperature co-fired ceramics (LTCC) is widely applied to the substrates, passive integrated devices, and module applications in wireless communication (Y. Imanaka 2005; Prabhakaran Sreekumari et al 2009). Some papers have reported several LTCC systems, such as glass + ceramics (multiphase ceramics) and glass-ceramics (crystallizable glass) (A. H. Kumar et al1981; R. R. Tummala et al 1991; S. H. Knickerbocker et al 1993). Typical systems include the borosilicate glass + alumina system developed by Fujitsu (Y. Imanaka and N. Kamehara 1992) and the lead borosilicate glass + alumina system by Dupont (J. I. Steinberg et al 1986). The glass phase and the crystalline phase determined the properties of the final glass + ceramics.

In some investigation, we may show a more interesting in the crystalline phase while the glass phase is expected to be disappeared. It will make great signification for investigating the crystallization kinetics of the LTCC. For example, by analyzing the microstructure of the LTCC, we can accurately calculate the volume fractions of crystalline phase through accounting the area of the crystalline phase, similarly, the nucleation rate and the size of the crystal my be calculated. In addition, when the glass phase was selectively removed from the LTCC, the porous layer will be left, this is benefit to lower the dielectric constant and dielectric loss. Bittner (2008) reported that a phosphoric-based acid may selectively etch the anorthite phase in the fired DP 951 AX LTCC. The Dupnt LTCC is made by firing an alumina and lead borosilicate glass blende, which generates a glass matrix with crystalline phases corundum, anorthite and alumina dispersed in it.

This paper introduce an effective method of selectively etching the glass phase of the LTCC A6 (Ferro) in the 19 $\mathrm{wt} \%$ sodium hydroxide aqueous solution. The analysis of the SEM and the X-ray diffraction confirm that only the glass phase was removed from the LTCC A6 (Ferro).

\section{Experimental}

A commercially available LTCC substrates (A6) from Ferro are used. The green tapes were laminated isostatically at a pressure of $32 \mathrm{Mpa}$ at $70^{\circ} \mathrm{C}$ and co-fired at peak temperature of $850^{\circ} \mathrm{C}$ for $30 \mathrm{~min}$ in a programmable furnace.

The LTCC surface was polished before etching. By consequent use of 2000\#, 3000\# and 5000\# sand papers, the as-fired LTCC samples were polished. Fig. 1 depicts the topography before and after polishing, indicating the planarization of the LTCC.

The etching of the LTCC was performed using a series of chemicals, including $1 \mathrm{wt} \%$ hydrochloride acid $(\mathrm{HCl})$, $2 \mathrm{wt} \%$ hydrofluoric acid (HF), $10 \mathrm{wt} \%$ hydro nitride acid $\left(\mathrm{HNO}_{3}\right)$, and $19 \mathrm{wt} \%$ sodium hydroxide $(\mathrm{NaOH})$. The condition of the etching as showed in Table 1.

The X-ray diffraction analysis, which determines any changes in phase composites before and after the etching, was conducted using a diffractometer 2500 TC from Rigaku, Japan. The X-ray beam has a wavelength of 0.154 $\mathrm{nm}$ corresponding to the $\mathrm{Cu} \mathrm{Ka}$-line. The microstructures of the LTCC were observed by a Scanning Electron Microscope (SEM), a Quanta 200 model from FEI, Holland. 


\section{Results and Discussion}

The etching rate was presented by the amount of LTCC etched per unit time and unit surface of exposed to the etching solution. Divided by the density of the LTCC, the etching rate can be represented as the depth of etching per unit time:

$$
v=\frac{M}{\rho A t}
$$

Where $v$ is the depth of etching per unit time, $M$ the mass of the LTCC etched, $\rho$ the density of the LTCC, $A$ the area of the LTCC exposed to the etching solution.

The etching rate obtained from the $19 \mathrm{wt} \%$ sodium hydroxide aqueous solution was given in the Table 2 as well the ones from $10 \mathrm{wt} \% \mathrm{HNO}_{3}, 1 \mathrm{wt} \% \mathrm{HCI}$, and $2 \mathrm{wt} \% \mathrm{HF}$ aqueous solution, respectively. The etching rates were calculated based on the amount of materials removed from the etchings, and the one from the sodium hydroxide was about $2.30 \mu \mathrm{g} / \mathrm{cm}^{2} \mathrm{hr}, 3$ to 4 orders of magnitudes lower than the etching rate from the $\mathrm{HCI}, \mathrm{HF}$ or $\mathrm{HNO}_{3}$.

The co-firing made Wollastonite $\left(\mathrm{CaSiO}_{3}\right)$ and Calciborite $\left(\mathrm{CaB}_{2} \mathrm{O}_{4}\right)$ precipitated and had them dispersed in the borosilicate glass. As shown in Fig. 1a, the glass phase covers the surface of the LTCC, apparently, the crystalline phase also be contained within the glass phase. The etchant could selectively remove the borosilicate glass and leave the crystalline phase almost unetched. When the unetched area is focused in a SEM observation, the etched area will be out of focus and remain dark in a field of view. The LTCC, however, has to be planer and smooth, so that the significant roughness and poor topography wouldn't misled the SEM observation. Fig. $1 \mathrm{~b}$ shows the LTCC after polished.

The sodium hydroxide selectively removed the glass phase as seen in the SEM images Fig. 2a, the LTCC surface has been porosified, the crystalline phase were bright and on the surface. The edges of the crystals were still sharp, and the planarization was still evident on the surface of the crystalline phase, the pores were apparently formed by selective etching of the glass, leading the area below the focus. Fig. $2 \mathrm{~b}, \mathrm{c}$ and d, also presented the SEM images obtained from the HCI, $\mathrm{HF}$ and $\mathrm{HNO}_{3}$ solution, respectively. Surface morphology showed that, in all the three cases, the etching was unselective.

The selectivity of etching can be confirmed with the X-ray diffraction of the LTCC before and after its exposure to the sodium hydroxide solution. As shown in Fig. 3, Wollastonite $\left(\mathrm{CaSiO}_{3}\right)$ and Calciborite $\left(\mathrm{CaB}_{2} \mathrm{O}_{4}\right)$ are the only two crystalline phases in the LTCC both before and after the etching. The two spectra before and after the etching also look quantitatively identical to each other, suggesting that the etching selectively removes the glass phase from the glass ceramics at room temperature after $20 \mathrm{hrs}$.

\section{Conclusions}

$1 \mathrm{wt} \%$ hydrochloride acid ( $\mathrm{HCl}), 2 \mathrm{wt} \%$ hydrofluoric acid ( $\mathrm{HF}), 10 \mathrm{wt} \%$ hydro nitride acid $\left(\mathrm{HNO}_{3}\right)$, have a larger etching rate than $19 \mathrm{wt} \%$ sodium hydroxide aqueous solution of $2.30 \mu \mathrm{g} / \mathrm{cm}^{2} \mathrm{hr}$. The clear microstructure of the LTCC can be obtained after the etching of the sodium hydroxide aqueous solution and the glass phase of the LTCC A6 (Ferro) can be selectively removed from the glass ceramics in a $19 \mathrm{wt} \%$ sodium hydroxide aqueous solution. This result will make contribute to the investigation for the porosificaiton and the crystallization kinetic of the LTCC.

\section{Acknowledgements}

I wish to express our thanks to Ferro and Seven Stars for supplying and laminating the A6 green tapes, respectively. The financial supports from Tianjin Polytechnic University is appreciated.

\section{References}

Bittner, A., Schmid, U. (2008). "The porosification of fired LTCC substrates by applying a wet chemical etching procedure." J. Eur. Ceram. Soc.

Imanaka Y. (2005). "Multilayers Low Temperature Cofired Ceramics (LTCC) Technology." Multilayers Springer, Berlin.

Imanaka, Y. and Kamehara, N. (1992). "Influence of Shrinkage Mismatch between Copper and Ceramics on Dimensional Control of the Multilayer Ceramic Circuit Board" J. Ceram. Soc. Jpn. Int. Ed., 100, 558-61.

Knickerbocker, S. H., Kumar, A. H. and Herron, L. W. (1993). "Cordierite Glass-Ceramics for Ceramic Packaging."Am. Ceram. Soc. Bull., 72 [I]: 90-95.

Kumar, A. H., McMillan, P. W. and Tummala, R. R. (1981). Glass-Ceramic Structures and Sintered 
Multilayered Substrates Thereof with Circuit Patterns of Gold, Silver, or Copper.’U.S. Pat. No. 4 301-324.

Prabhakaran Sreekumari Anjana and Mailadil Thomas Sebastianw (2009). "Microwave Dielectric Properties and Low-Temperature Sintering of Cerium Oxide for LTCC Applications.” J. Am. Ceram. Soc., 92 [1]: 96-104 .

Steinberg, J. I., Horowitz, S. J. and Bacher, R. J. (1986). "Low-Temperature Co-Fired Tape Dielectric Material Systems for Multilayer Interconnections.” American Ceramic Society 19: 31-39.

Tummala, R. R. (1991). "Ceramic and Glass-Ceramic Packaging in the 1990s.” J. Am. Ceram. Soc., 74: 895-908.

Table 1 . The etching time of the LTCC (A6) at $25^{\circ} \mathrm{C}$ in a $19 \mathrm{wt} \%$ sodium hydroxide aqueous solution and in the other three control etchants.

\begin{tabular}{|c|c|}
\hline Etching solution & Etching time \\
\hline $19 \mathrm{wt} \% \mathrm{NaOH}_{\text {aqueous }}$ & $20 \mathrm{hr}$ \\
\hline $10 \mathrm{wt} \% \mathrm{HNO}_{3}$ aqueous & $60 \mathrm{~s}$ \\
\hline $1 \mathrm{wt} \% \mathrm{HCl}$ aqueous & $30 \mathrm{~s}$ \\
\hline $2 \mathrm{wt} \% \mathrm{HF}$ aqueous & $10 \mathrm{~s}$ \\
\hline
\end{tabular}

Table 2. The etching rates of the LTCC (A6) at $25^{\circ} \mathrm{C}$ in a $19 \mathrm{wt} \%$ sodium hydroxide aqueous solution and in the other three control etchants.

\begin{tabular}{|c|c|}
\hline Etching solution & Etching rates $\left(\mu \mathrm{g} / \mathrm{cm}^{2} \mathrm{hr}\right)$ \\
\hline $19 \mathrm{wt} \% \mathrm{NaOH}$ aqueous & 2.30 \\
\hline $10 \mathrm{wt} \% \mathrm{HNO}_{3}$ aqueous & $2.92 \times 10^{3}$ \\
\hline $1 \mathrm{wt} \% \mathrm{HCl}$ aqueous & $5.04 \times 10^{3}$ \\
\hline $2 \mathrm{wt} \% \mathrm{HF}$ aqueous & $1.69 \times 10^{4}$ \\
\hline
\end{tabular}
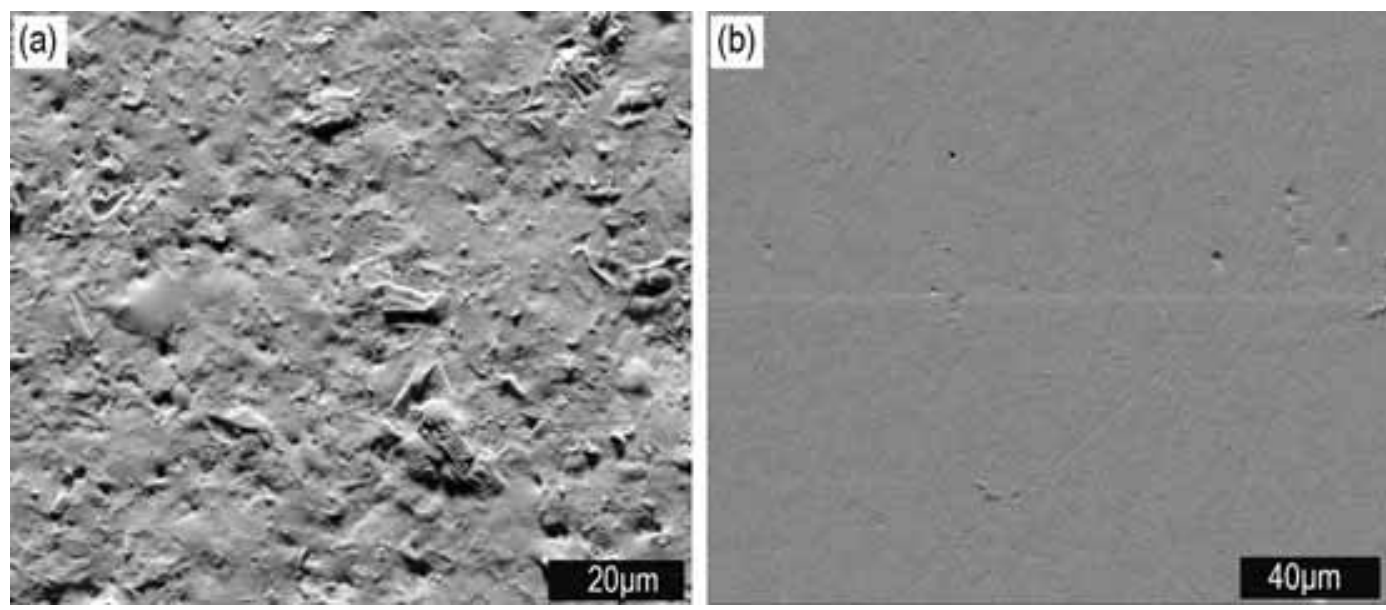

Figure 1. The surface topography of the LTCC (A6) from SEM, (a) before polishing, (b) after polishing 

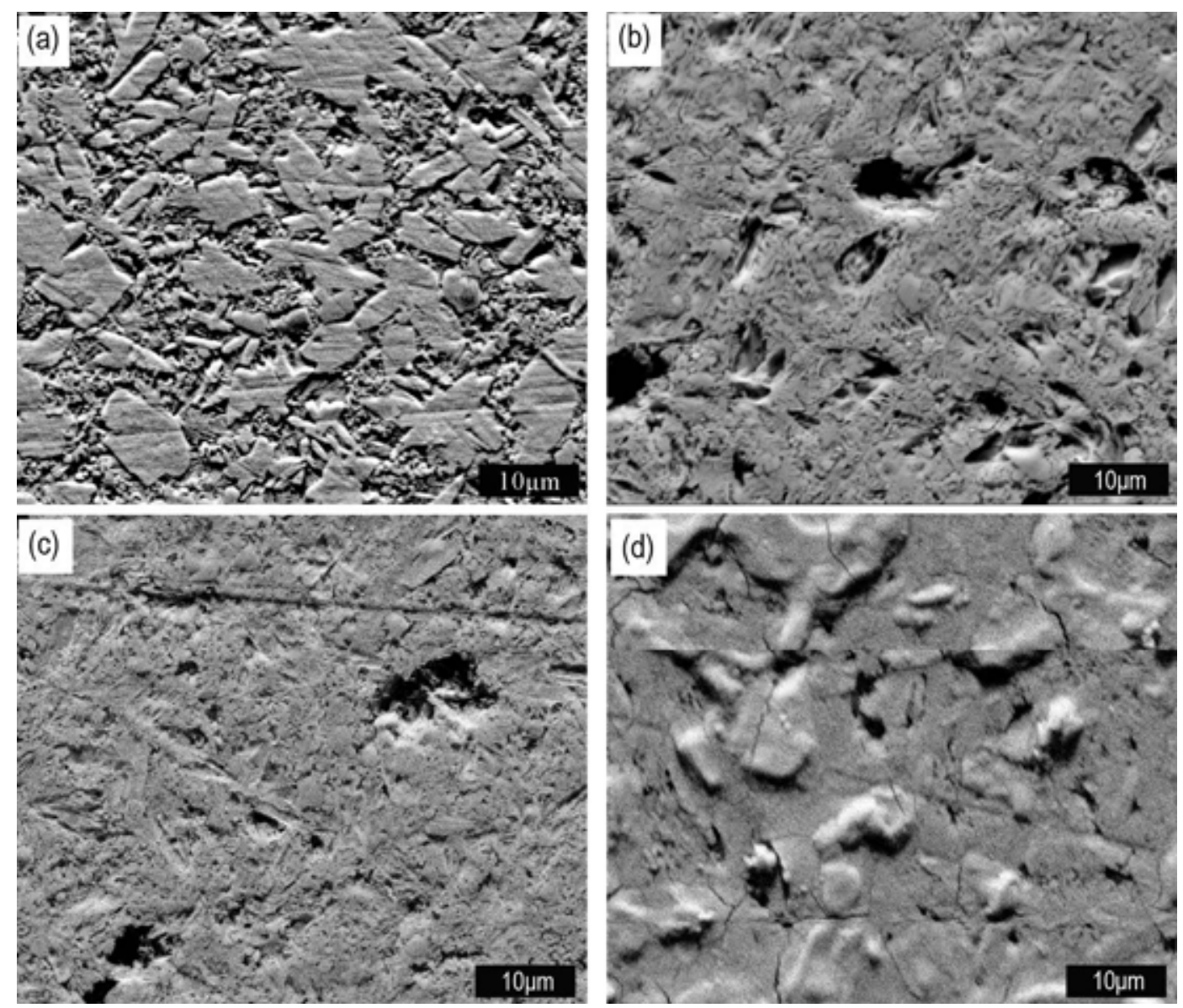

Figure 2. The SEM images of the LTCC (A6) surfaces after etched at $25^{\circ} \mathrm{C}$ for $20 \mathrm{hrs}$ in (a) $19 \mathrm{wt} \% \mathrm{NaOH}$, (b) $10 \mathrm{wt} \% \mathrm{HNO}_{3}$, (c) $1 \mathrm{wt} \% \mathrm{HCl}$, and (d) $2 \mathrm{wt} \% \mathrm{HF}$, respectively.

All the LTCCs were polished to a mirror finish before etching.

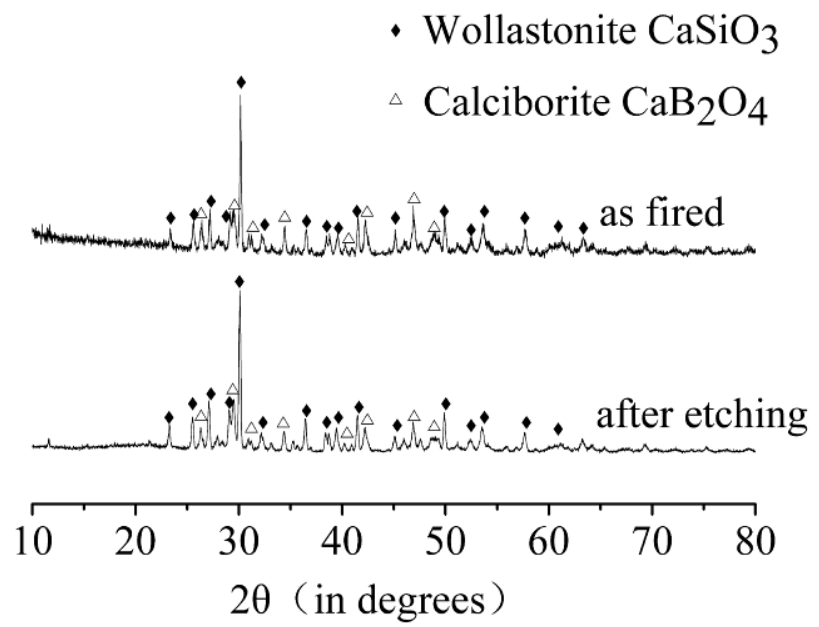

Figure 3. The X-ray diffraction spectra of the LTCC (A6) before (as-fired) and after the exposure to a $19 \mathrm{wt} \%$ sodium hydroxide aqueous solution for $20 \mathrm{hrs}$ 